\title{
A REFORMA DE BASE NO ENSINO DA HISTÓRIA PÁTRIA: O PROJETO DA HISTÓRIA NOVA DO BRASIL*
}

\author{
Lucia Maria Paschoal Guimarães \\ Universidade do Estado do Rio de Janeiro \\ Nanci Leonzo \\ Universidade de São Paulo
}

\begin{abstract}
Resumo
Este artigo examina o projeto da História Nova do Brasil - um conjunto de fascículos publicado às vésperas do golpe militar de 1964, pela Campanha de Assistência ao Educando (CASES), do então Ministério da Educação e Cultura. A coleção destinava-se a professores e alunos de nível médio e foi concebida por docentes do Instituto Superior de Estudos Brasileiros, a propósito de promover a revisão dos conteúdos dos livros didáticos de história do Brasil, por meio de uma abordagem marxista.
\end{abstract}

\section{Abstract}

This article examines the História Nova do Brasil project, a series of booklets published by the Ministry of Education and Culture through its Student Aid Campaign, on the eve of the 1964 military coup. Developed by specialists in the Higher Institute of Brazilian Studies (ISEB) and addressed to an audience of secondary teachers and students, the new series sought to revise the content of Brazilian history textbooks, by adopting a Marxist approach.

\section{Pallavras-Chave}

História Nova do Brasil • Marxismo • Ensino de História • Livro Didático • Revolução Brasileira

\section{Keywords}

História Nova do Brasil • Marxism • History Teaching • Didatic Books • Brazilian Revolution

\footnotetext{
* Este trabalho é tributário de uma investigação realizada pelas autoras para a Comissão de História da Historiografia, do Comitê Internacional de Ciências Históricas. A versão original do texto ora
} 
(...) Na historiografia brasileira, daqui por diante, há duas fases: antes da História Nova e depois dela...

A afirmação é de Nelson Werneck Sodré (1911-1999), militar de carreira e intelectual, um dos principais teóricos do Partido Comunista Brasileiro (PCB) nas décadas de 1950-1960, e que também por muitos é considerado o historiador oficial do Partido (Moraes 1995: 80 e Mantega 1995: 112). Quanto à obra História Nova, cabe, de início, conceituá-la, justamente por se tratar de uma tentativa de proporcionar aos professores e alunos de escolas de nível médio um conjunto de textos que permitissem, segundo o mesmo Werneck Sodré, (...) mostrar aos jovens as verdadeiras razões históricas dos acontecimentos, atraindo-os para uma ciência apta a enriquecer-lhes o espírito (Sodré 1987: 121). Entendendo-se como ciência apta, o marxismo.

No início dos anos sessenta, durante a gestão do Presidente João Goulart (19611964), intensificou-se o debate sobre a questão nacional. No plano econômico, a discussão se concentrava na problemática da autonomia nacional e da dependência do país em relação ao capital estrangeiro, ao mesmo tempo em que se formulavam propostas alternativas no sentido de superar as condições históricas do subdesenvolvimento. Do ponto de vista político, a contenda girava em torno das estruturas básicas da sociedade brasileira, com os setores de esquerda, pressionando o governo para institucionalizar as reformas agrária, bancária, eleitoral, universitária, etc. Mobilização, cabe acrescentar, que reunia desde os políticos da Frente Parlamentar Nacionalista até a Confederação Geral dos Trabalhadores (CGT), passando pela União Nacional dos Estudantes (UNE).

Os ventos reformistas sopravam em todas as direções. Desafiar as chamadas “estruturas arcaicas" estava na ordem do dia. No campo da educação, dentre outras iniciativas, o projeto de Paulo Freire, já em andamento, vinha desencadeando uma verdadeira campanha cívico-popular. Seu método de alfabetização de adultos pretendia reverter a curto prazo o quadro secular do analfabetismo, que marginalizava milhões de brasileiros. Outras experiências procuravam sacudir a inércia cultural

divulgado, com o título Nacionalismo e Marxismo no Ensino de História do Brasil: o projeto da História Nova, foi apresentada em Moscou, julho de 2001, no Simpósio Intelectuais e Marxismo na América Latina, durante o X Congresso Internacional da FIEALC. 
como foi o caso das atividades fomentadas pelo Centro de Cultura Popular (CPC) da UNE, que levavam o teatro, o cinema e a literatura às camadas populares, a propósito de engajá-las no processo social e político (Fernandes 1974: 5-22). A efervescência era tal, que nos meios intelectuais anunciava-se que o país já estaria vivenciando, de fato, um processo revolucionário: (...) Esta revolução, entre nós, denomina-se Reformas de Base. Toda revolução pacífica ou violenta, tem de importar em reforma de base, ou não será revolução (Duarte 1963: 40).

O momento, portanto, também se mostrava oportuno para ensaiar uma reforma no ensino da história pátria. Tanto assim, que em 1963, com a finalidade de promover a revisão dos conteúdos dos livros didáticos de história do Brasil, dois órgãos do então Ministério da Educação e Cultura celebraram um convênio, visando à edição de uma coletânea de textos, destinados aos professores de história, para uso nos colégios da rede oficial e particular de nível médio: a Campanha de Assistência ao Educando (CASES) e o Instituto Superior de Estudos Brasileiros (ISEB). A parceria fora iniciativa de Roberto Pontual, antigo estagiário do Instituto, que havia assumido a direção da Campanha de Assistência ao Educando. Por ocasião do lançamento dos primeiros fascículos, a título de apresentação, Roberto Pontual justificaria a relevância do empreendimento, face o contexto sócio-histórico que o país atravessava: (...) A história do Brasil, tradicionalmente concebida e comunicada, em especial na literatura didática, longe de revelar as verdadeiras bases do processo de formação do nosso país, vem servindo, pelo contrário, como instrumento de freios e desvios, obstáculo para o seu próprio desdobramento. No seu entender, o trabalho a ser desenvolvido pelos especialistas do ISEB deveria sanar essas deficiências e contribuir, (...) à sua maneira, para o desenvolvimento coerente e acelerado do processo histórico brasileiro ${ }^{1}$.

Sob a designação História Nova, programou-se a organização de 10 livretos, a serem produzidos pelo Departamento de História do Instituto Superior de Estudos Brasileiros. O plano da obra previa a publicação dos seguintes títulos: $O$ descobri-

${ }^{1}$ Cf. Roberto Pontual (Diretor da Campanha de Assistência ao Educando), "Apresentação" à coleção de 1964. Esta Texto que também foi incorporado à publicaçao comemorativa de 1993. 
mento do Brasil; A sociedade do açúcar; As invasões holandesas; A decadência do regime colonial; A independência de 1822; Da Independência à República; O sentido da Abolição; $O$ advento da República e O significado do Florianismo. Envolvidos na consecução do projeto, além de Nelson Werneck Sodré, que na época chefiava aquele Departamento, estavam cinco jovens colaboradores: Mauricio Martins de Mello, Pedro de Alcântara Figueira, Pedro Celso Uchôa Cavalcanti Neto, Rubem Cesar Fernandes e Joel Ruffino dos Santos. Os quatro primeiros eram professores de ensino médio, recém egressos do Curso de História da então Faculdade Nacional de Filosofia da Universidade do Brasil, hoje em dia Universidade Federal do Rio de Janeiro. Joel Rufino, embora ainda freqüientasse os bancos acadêmicos, fora indicado para fazer parte do grupo pelo Centro de Estudos de História da referida Faculdade, grêmio estudantil que era controlado pelo Partido Comunista Brasileiro (Santos 1993: 15).

É importante notar que houve três edições diferentes da História Nova. No presente trabalho iremos tratar, em especial, da problemátiva relativa ao lançamento da primeira edição, chancelada pelo Ministério da Educação e Cultura, datada de 1964, ocasião em que foram publicados os seguintes fascículos: $O$ descobrimento do Brasil; As invasões holandesas, A expansão territorial, A independência de 1822 e Da Independência à República ${ }^{2}$.

À guisa de informação, vale salientar que em 1965 saiu uma segunda edição, com o título História Nova do Brasil, quando a Editora Brasiliense tomou para si a tarefa de reiniciar o projeto, interrompido em virtude do golpe militar de 1964, como veremos mais adiante. Pela Brasiliense, ao invés dos dez títulos inicialmente propostos foram publicados sete, reunidos em dois volumes, obedecendo a uma certa periodização. No primeiro, reaparecem as monografias $O$ descobrimento do Brasil; As invasões holandesas, A expansão territorial, acrescidas de uma inédita, $A$ sociedade do açúcar. O outro volume agrega três contribuições originais, que inte-

\footnotetext{
${ }^{2}$ MEC/ISEB, O descobrimento do Brasil, Rio de Janeiro:MEC/ISEB, 1964. (Coleção História Nova 1). MEC/ISEB, As invasões holandesas, Rio de Janeiro:MEC/ISEB, 1964. (Coleção História Nova 3); MEC/ISEB, A expansão territorial, Rio de Janeiro:MEC/ISEB, 1964. (Coleção História Nova 4); MEC/ISEB, A independência de 1822, Rio de Janeiro:MEC/ISEB, 1964. (Coleção História Nova 6) e MEC/ISEB, Da Independência à República (Evolução da economia brasileira). Rio de Janeiro: MEC/ISEB, 1964. (Coleção História Nova 7).
} 
gravam o plano do ISEB: $O$ sentido da Abolição; $O$ advento da República e $O$ significado do Florianismo.

Tanto a versão do MEC, quanto a da Editora Brasiliense foram censuradas e apreendidas pelos governos da ditadura militar. Finalmente, por ocasião da passagem do trigésimo aniversário do lançamento dos primeiros livretos da coletânea, preparou-se uma publicação comemorativa, denominada História Nova do Brasil (19631993). Organizado como lugar de memória (Nora 1984: XXVI), este novo livro privilegiou os depoimentos dos autores sobre o trabalho desenvolvido no ISEB e seus desdobramentos políticos. Ou seja, traz o relato da repressão por eles sofrida com o advento dos governos militares. Das duas versões anteriores, a obra traz somente a monografia $O$ descobrimento do Brasil, preservadas as características editoriais do lançamento da Brasiliense.

Antes de prosseguirmos, convém abrir aqui um ligeiro espaço para tecer algumas considerações a respeito das origens do Instituto Superior de Estudos Brasileiros. Criado em 14 de julho de 1955, no âmbito do Ministério da Educação, o Instituto não possuía vinculação direta com a universidade. Destinava-se a promover (...) o estudo, o ensino, a divulgação das ciências sociais, notadamente da sociologia, da história, da economia e da política, especialmente para o fim de aplicar as categorias e os dados dessas ciências à análise e à compreensão crítica da realidade brasileira, visando à elaboração dos instrumentos teóricos que permitam o incentivo e a promoção do desenvolvimento brasileiro $^{3}$. Em síntese, o seu propósito era formular uma teoria nacional-desenvolvimentista (Chilcote 1982: 116-117 e Santos 1985: 7-8).

Segundo Alberto Guerreiro Ramos, um isebiano de primeira hora ${ }^{4}$, a estrutura do novo reduto intelectual inspirava-se no modelo de organização do Colégio de França. Em entrevista concedida a Alzira Alves de Abreu e Lucia Lippi Oliveira, em 1981, Guerreiro frisaria que o propósito era de instituir (...) um órgão que reconhecesse as pessoas que não têm carreira na universidade, mas que são grandes

\footnotetext{
${ }^{3}$ Decreto $n^{\circ} 37.608$, de 14 de julho de 1955.

${ }^{4}$ Caio Navarro de Toledo, a propósito da composição dos quadros dirigentes do ISEB, identifica como isebianos históricos Guerreiro Ramos, Cândido Mendes de Almeida, Hélio Jaguaribe, Nelson Werneck Sodré, Roland Corbisier e Álvaro Vieira Pinto.
} 
luminares, não importa que tenham título ou não. A proposta representava, pois, (...) uma idéia muito, muito alta. (...) uma instância de processamento do pensamento brasileiro (Oliveira 1995: 155-157).

Na verdade, a dita idéia não seria tão original, quanto sugere esse isebiano histórico. Na década de 1910, um dos próceres do nacionalismo brasileiro, o sociólogo e pensador Alberto Torres, sugeriu que Instituto Histórico e Geográfico Brasileiro encabeçasse um movimento em prol da criação de um organismo, que congregasse as grandes notabilidades da inteligentzia brasileira, com o intuito de promover (...) o estudo dos problemas práticos da terra e da nacionalidade brasileira, dos seus habitantes, e de sua sociedade ${ }^{5}$. Alberto Torres, inclusive, incorporaria essa proposição, ao formular o seu conhecido projeto de revisão constitucional (Torres 1933: 513-514).

Não vem ao caso, no momento, levantar a discussão acerca das diversas vertentes ideológicas, que influenciaram os conceitos difundidos pelo ISEB ao longo da trajetória. Nem tratar dos embates teóricos sobre o nacionalismo que ali tiveram lugar e redundaram no afastamento de certos isebianos de primeira hora, a exemplo do cientista político Hélio Jaguaribe e do próprio Guerreiro Ramos, que durante certo tempo exerceu uma espécie de liderança intelectual na instituição. Questões, aliás, que já foram objeto da atenção de especialistas, como Caio Navarro de Toledo. Por ora, interessa-nos apenas pontuar que, após atravessar um período adverso, permeado de cisões intestinas, ataques externos e corte de verbas orçamentárias (Sodré 1978: 58-19), o ISEB voltaria a desfrutar de prestígio no cenário político e cultural do país, no início da década de 60. Mais precisamente, quando João Goulart assumiu o poder. Sob a orientação teórica e política de Álvaro Vieira Pinto e de Nelson Weneck Sodré, o órgão cerrou fileiras na campanha pela volta ao regime presidencialista, por ocasião do plebiscito realizado em 01 de janeiro de $1962^{6}$. Logo em

\footnotetext{
${ }^{5}$ Cf. Alberto Torres, "Discurso de posse no IHGB" Revista do IHGB, Rio de Janeiro, 74 (126): 595596, 1911.

${ }^{6}$ Em decorrência da crise política gerada pela a renúncia do Presidente Jânio Quadros, o Congresso Nacional aprovou, em 2 de setembro de 1961, Ato adicional no 4 à Constituição de 1946, instuindo o regime parlamentarista no Brasil. A solução negociada entre políticos e militares, que viabilizou a posse do então Vice-Presidente João Goulart, seria rejeitada pelo plebiscito realizado em 01 de janeiro de 1962.
} 
seguida, engajou-se na luta pelas reformas de base. Neste sentido, além dos cursos regulares que habitualmente oferecia, o órgão intensificou suas atividades junto a entidades sindicais e estudantis, promovendo seminários e conferências. Ao mesmo tempo, promoveu a renovação dos seus quadros docentes, com a crescente incorporação de jovens professores e líderes do movimento estudantil.

Nelson Werneck Sodré integrou-se ao grupo dos fundadores do ISEB, a convite de Guerreiro Ramos. A princípio, segundo suas próprias palavras, desempenhou um papel secundário na hierarquia isebiana, encarregado apenas de ministrar os cursos de história do Brasil ${ }^{7}$. Oficial do Exército, pertencia à corrente militar ultranacionalista liderada pelo Gen. Newton Estillac Leal. Na caserna, desfrutava de grande prestígio entre seus pares, não só pelas posições políticas que defendia, mas principalmente pelos sólidos estudos e publicações que realizara sobre a realidade brasileira. Erudito, sua vasta produção intelectual também era reconhecida nos meios civis. O livro Panorama do Segundo Império, por exemplo, lançado pela primeira vez em 1940, posteriormente veio a fazer parte da prestigiosa Coleção Brasiliana, da Companhia Editora Nacional.

Apesar de nunca ter ocupado funções dirigentes no PCB, Nelson Werneck Sodré exercia notável influência sobre o comunismo brasileiro. Sustentava de modo intransigente o nacionalismo como prática política, adequada ao cenário histórico em que se encontrava a formação social brasileira :

(...) O Nacionalismo surge da necessidade de compor um novo quadro conjugando interesses de classe, reduzindo-os a um denominador mínimo comum, para a luta em defesa do que é nacional em nós. É o imperativo de superar a contradição entre a burguesia nacional e a classe trabalhadora que adota o Nacionalismo como expressão portuna de uma política (Sodré 1959: 36).

Argumentava que no país, entre as décadas de 1930 e 1950, desenvolveram-se forças produtivas capitalistas, representadas por um conjunto de fatores, destacandose a implantação de um parque industrial, a crescente urbanização, a mobilização

\footnotetext{
${ }^{7}$ Sodré integrava o Departamento de História, cuja chefia naquela ocasião era exercida por Cândido Mendes de Almeida.
} 
das massas de trabalhadores que teriam adquirido consciência política e pelo surgimento de uma nova composição social no país, o que inclui a organização de uma burguesia nacional capaz de realizar-se como classe (Sodré 1959: 38-39). Caberia a esta burguesia nacional implementar um projeto de desenvolvimento capitalista autônomo. Para tanto, seria obrigada a defrontar-se com as forças do imperialismo, especialmente o de origem norte-americana, e seus aliados internos: o latifúndio semi-feudal e setores da burguesia comercial. Estratégia etapista, diga-se de passagem, calcada numa aplicação mecânica do materialismo clássico.

Ao longo dos anos 1950-60, as teses formuladas por Sodré constituíram o fundamento teórico das posições programáticas do PCB (Moraes 1995: 80). Suas premissas embasaram as diretrizes aprovadas durante a realização do IV Congresso do PCB, cujo mote se resumia em (...) saber convencer e desmascarar. Do mesmo modo, estão subjacentes aos princípios firmados na Declaração de Março de 1958, quando o Partido resolveu romper com as táticas insurrecionistas e com o dogmatismo fomentado pela importação de modelos teóricos ${ }^{8}$, optando por um caminho pacífico, que levasse à conquista do que denominava de regime nacional-democrático (Mantega 1995: 111-112).

Seja como for, a proposta do Ministério da Educação de confiar ao ISEB, em particular a Nelson Werneck Sodré, a tarefa da elaboração da História Nova ajustava-se como uma luva aos propósitos do Partido. Sobretudo, quando se levarmos em conta o público-alvo que se pretendia atingir: num primeiro momento, os professores secundários e, em seguida, por efeito multiplicador, as novas gerações de estudantes. A mesma estratégia, aliás, há muito que vinha sendo utilizada nos países do sistema soviético, como se pode depreender das conclusões do historiador húngaro Ferenc Glatz, na contribuição Politics and Historical Science in the Countries of the Sivuet System, onde se lê: (...) Teacher trainig was a political issue, the teacher was the the representative of the political ideology (official aproach to History). (...) History was used as the raw material for political propaganda. Historical knowledge was a tool for political propaganda. Historical science was a politically science exposed (Glatz 1995: 14-17). ${ }^{8}$ O IV Congresso do PCB realizou-se entre 7 e 11 de novembro de 1954 . Até então, o PCB seguia o
modelo de revolução para os países coloniais, formulado pela Internacional Comunista em 1928. 
Do ponto de vista da historiografia marxista no Brasil, porém, é importante realçar que a coletânea preparada pelo ISEB não se constituía numa experiência pioneira. Outra obra detém esta primazia, embora não estivesse voltada para a difusão das interpretações advindas do materialimo histórico, ao nível do ensino médio. Trata-se da Evolução política do Brasil, escrita pelo Professor Caio Prado Júnior. em 1933. Apesar do vanguardismo deste estudioso, que publicou na década de 1940 um outro ensaio clássico, a História econômica do Brasil, suas idéias tiveram repercussão limitada no âmbito da cúpula do Partido Comunista, que em certos momentos chegou mesmo a censurá-lo ${ }^{9}$. Ao contrário de Nelson Werneck Sodré, Caio Prado Júnior recusava-se a aceitar a tese de que o hinterland brasileiro possuía relações semi-feudais ou pré-capitalistas (Prado Júnior 1966: 79).

Mas voltemos à História Nova, objeto central da nossa discussão. Segundo o depoimento de um dos seus autores, Pedro de Alcântara Figueira, a militância comunista, revestida do nacionalismo fora de fato o fio condutor da polêmica obra. Vista como um passo errado, trinta anos mais tarde por Pedro de Alcântara, essa postura revisionista não deve ser levada a sério (Figueira 1993: 42). No fundo, o que se propunha naquela ocasião era renovar os estudos brasileiros e instaurar um novo olhar sobre esses estudos. Para Nelson Weneck Sodré:

(...) O novo corresponde, por isso mesmo, a uma visão de conjunto em que as partes se compõem na sua relatividade, e denuncia todas as idéias como historicamente condicionadas, isto é, peculiares a determinado tempo e a determinado meio e jamais eternas e absolutas receitas universais, diante das quais todos se deveriam curvar sem análise (Sodré 1963: 166).

Na teoria, o projeto visava combater um tipo de ensino que Sodré e seus discípulos consideravam tradicional. Crítica, por sinal, bem procedente,

\footnotetext{
${ }^{9}$ Dentre os militantes do PCB que rejeitaram as teses de Caio Prado Jr, em diferentes momentos, veja-se, por exemplo, Rivadávia Mendonça, "O estudo da história e a realidade brasileira". Imprensa Popular, Rio de Janeiro, 01 de agosto de 1954. Suplemento: 2 e 6. Ver, ainda, Assis Tavares, "Caio Prado e a teoria da revolução brasileira". Revista Civilização Brasileira, Rio de Janeiro, 1 (11/12): 48-80, dezembro 1966/março 1967.
} 
considerando o tratamento descontextualizado e linear que os livros didáticos costumavam dispensar à narrativa dos acontecimentos do nosso passado. Porém, na prática, a proposta de renovação do grupo do ISEB pretendia, sobretudo, dar à história uma função pragmática, na medida em que ela deveria auxiliar na construção de (...) bases seguras para todas as iniciativas a fluir daqui para frente" (Sodré 1963: 61-62). Ou seja, em última análise direcionava-se o estudo da história para o que os autores inspirados em Nelson Werneck Sodre denominavam de revolução brasileira (Cavalcanti Neto 1993: 63).

Valendo-se de um método de elaboração socializado, os autores da História Nova dividiram o tempo histórico em episódios. Havia um relator para cada episódio, escolhido por todos e variável, encarregado de escrever uma espécie de rascunho preparatório. Cada integrante do grupo estudava e anotava essa versão preliminar, segundo suas pesquisas individuais. A seguir, a equipe se reunia para debater não só o texto proposto, mas também as contribições apresentadas. Após intensa discussão, era redigido em conjunto o texto definitivo, que ainda seria objeto de nova leitura e revisão (Sodré 1993: 33).

Até fevereiro de 1964, conforme já dissemos, haviam sido publicados cinco volumes da pretendida coleção: $O$ descobrimento do Brasil; As invasões holandesas, A expansão territorial, A independência de 1822 e Da Independência à República,. Evidenciando o maior interesse em promover a difusão da obra, o Ministério da Educação e Cultura, baixou a Portaria n ${ }^{\circ}$ 50, de 04 de fevereiro de 1964, na qual recomendava expressamente a utilização da História Nova nas escolas, a propósito de suprir:

(...) as deficiências da historiografia no sentido de apresentar aos professores de grau médio um conjunto de informações sistemáticas que os habilite a melhor preparação de seus cursos, considerando que a coleção (...), ora editada (...), contribui com importantes subsídios para que tais deficiências sejam sanadas.

A mesma Portaria fixava, ainda, que a Campanha de Assitência ao Educando deveria providenciar a remessa gratuita dos livretos (...) a todos os professores de história de ensino de grau médio de todo o país ${ }^{10}$. Determinação, ao que tudo indica,

${ }^{10}$ Cf. Ministério da Educação e Cultura, "Portaria n ${ }^{\circ} 50$ de 04 de fevereiro de 1964. Diário Oficial. Brasília, 12 de fevereiro de 1964, Seção I Parte I, p. 1346. 
teria sido cumprida à risca, pois em menos de um mês foram distribuídos pelo correio cerca de cinco mil exemplares, contemplando todos os docentes registrados nos cadastros do MEC (Cavalcanti Neto 1993: 61).

Além disso, o Ministério alterou as normas que regulamentavam a compra de livros didáticos para serem utilizados nas escolas, com recursos do governo federal. Diga-se de passagem, um filão do mercado editorial muito disputado por autores e empresários do ramo. De acordo com o disposto no Decreto ${ }^{\circ} 53.583$, de 21 de fevereiro de 1964, as obras publicadas pelo MEC passavam a figurar obrigatoriamente entre os títulos selecionados, para integrar as bibliografias indicadas por estabelecimentos públicos e privados, nas diferentes disciplinas e séries, tanto do curso elementar, quanto do de nível médio ${ }^{11}$. Medida que também iria impulsionar a chegada da História Nova às salas de aula.

Apesar dessa mobilização, a projetada reforma de base do ensino da história pátria morreu no nascedouro. Em abril daquele mesmo ano, após o golpe de Estado que derrubou o Presidente João Goular, o Instituto de Estudos Brasileiros teve suas portas cerradas e a sede destruída ${ }^{12}$. Suas publicações, documentos e arquivos queimados. Os exemplares da História Nova foram apreendidos e seus responsáveis presos. A exceção de Nelson Werneck Sodré, os demais autores amargaram anos de exílio, enquanto perduraram os governos militares ${ }^{13}$.

Se a História Nova se constituiu no produto de um trabalho coletivo, a censura que sofreu também foi coletiva. Logo após o seu aparecimento, tanto pela imprensa, como pela televisão, não foram poucas as vozes que se levantaram contra a sua adoção compulsória nos colégios. Basta dizer que somente o jornal O Estado de S. Paulo dedicou cinco editoriais, criticando não apenas o conteúdo da recém lançada coleção, mas também o caráter obrigatório do seu uso, o que qualificou de (...) prenúncio do Estado Totalitário de Amanhã. Sem história ou com várias estórias, todas reescritas

\footnotetext{
${ }^{11}$ Cf. Ministério da Educação e Cultura, "Decreto no 53583", de 21 de fevereiro de 1964. Diário Oficial Brasília, 24 de fevereiro de 1964, Seção I, Parte I, p. 1423-1424.

${ }^{12}$ Formalmente, o Instituto Superior de Estudos Brasileiros foi extinto pelo Decreto $\mathrm{n}^{\circ}$ 53.884. $\mathrm{Di}$ ário Oficial. Brasília, 13 de abril de 1964, p. 3283.

${ }^{13}$ Ver "Denúncia oferecida pelo Procurador-Geral da Justiça Militar" contra os autores da História Nova. Revista da Civilização Brasileira, Rio de Janeiro, 11-12: 208-212, dezembro/1966-março/1967.
} 
e reformadas conforme os interesses de dominação política dos intelectuais do regime ${ }^{14}$. No Rio de Janeiro, dentre outros diários, o Jornal do Brasil externou o seu repúdio pelo que denominava de dirigismo pedagógico do governo ${ }^{15}$.

Na contenda entre a "direita" e a "esquerda", até o veterano Instituto Histórico e Geográfico Brasileiro seria convocado pela Liga da Defesa Nacional para se manifestar. Afinal, a centenária instituição, desde 1838 vinha sendo responsável pela construção da memória nacional. Não custa lembrar que ao inventar as tradições do país recém independente, o Instituto Histórico, afinado com o projeto político em curso, contribuiu para legitimar o Estado monárquico, transformando-o no legítimo herdeiro e sucessor do império ultramarino português. Legado que se sustentava, inclusive, com a presença de um representante da dinastia de Bragança no Trono Brasileiro. Subjacente a esta idéia, forjou-se, ainda, o conceito de que a passagem do estatuto de colônia para o de país independente fora um processo natural, caracterizado pela ausência de traumas e rupturas. Marca singular, que diferenciava os brasileiros, dos seus vizinhos sul americanos (Guimarães 1995: 523).

A essa memória, obviamente, correspondia uma determinada concepção de história, também marcada pelo pragmatismo, a qual um outro projeto, não menos pragmático, o da História Nova, pretendia desautorizar. E com uma agravante, com o aval do Ministério da Educação, (...) adotada quase por decreto, conforme sublinhou anos mais tarde Francisco Iglésias (Iglésias 2000: 235). Do ponto de vista da historiografia, portanto, tratava-se de um duelo entre duas histórias oficiais.

Alinhada com os setores anti-comunistas, a repulsa do Instituto Histórico e Geográfico Brasileiro ao trabalho dos professores do ISEB veio através de um longo parecer, onde se condenava a utilização do modelo marxista, apresentado como a única interpetação capaz de explicar os fatos históricos ${ }^{16}$. A par disso, a pretexto da

\footnotetext{
${ }^{14}$ Cf. "História Nova 5". O Estado de S. Paulo. São Paulo, 14 de março de 1964, p. 3. Ver, ainda, os seguintes editoriais "História Nova 1". O Estado de S. Paulo. São Paulo, 03 de março de 1964, p. 3; "História Nova 2", O Estado de S. Paulo. São Paulo, 04 de março de 1964, p. 3; "História Nova 3". O Estado de S. Paulo. São Paulo, 07 de março de 1964, p. 3; "História Nova 4". O Estado de S. Paulo. São Paulo, 11 de março de 1964, p. 3. "História Nova 5". São Paulo, 14 de março de 1964, p. 3.

15 "Revolução da Ignorância". Jornal do Brasil, Rio de Janeiro, 06 de fevereiro de 1964, p. 6.

${ }^{16}$ Cf. Revista do Instituto Histórico e Geográfico Brasileiro, Rio de Janeiro; 263 (2): 283-302, abril-junho de 1964
} 
defesa da liberdade didática, garantida pela Lei de Diretrizes e Bases da Educação então em vigor (Lei n 4024/61), os censores do Instituto Histórico vetavam a intenção declarada de intervir na memória nacional, pela via dos manuais de ensino. Literatura que sempre teve capital importância na preservação da memória coletiva, tanto pelo seu caráter ideológico, quanto pela persistência de modelos mais ou menos mitificadores, que identificavam os exemplos a serem seguidos pela juventude (Crubellier 1986: 434-436).

Como acontece com frequiência em história, a distância permite o desejo e a possibilidade de estudar certos assuntos polêmicos (Joutard 1977: 10). Passadas quase quatro décadas do lançamento de obra tão polêmica, uma última consideração se faz necessária. É inegável que o enfoque proposto pela História Nova trazia um significativo arejamento ao ensino da história, à medida em que expandia os horizontes da história do Brasil, articulando-a ao quadro da história geral. Incorporava, também, pela primeira vez, o estudo das determinantes econômicas nos textos destinados às classes do ensino médio. Um exemplo pontual dessa abordagem pode ser percebida na monografia intitulada $O$ descobrimento do Brasil. O tema vem precedido por uma cuidadosa, ainda que severa, revisão de toda a literatura didática disponível, o que representava um avanço na exposição da matéria em livros do gênero. As brechas identificadas no exame crítico são exploradas ao longo da monografia, que se inicia descortinando o panorama europeu do final da idade média. Esboçado o pano de fundo, a situação do Reino de Portugal vem para o primeiro plano, com o exame das linhas gerais de sua evolução social e econômica. Tais aspectos são articulados às condições e características da empresa mercantil ultramarina lusitana, da qual o Brasil era parte integrante.

Mas, por outro lado, o projeto apresentava graves distorções na interpretação de uma boa parcela do nosso passado. Marxismo apressado, por certo (Iglésias 2000: 234-235). Dessa visão decorreria uma série de tropeços, derivados, principalmente, da insistência com que se procurou subordinar ao viés econômico o papel desempenhado por certos vultos da história pátria. Ou, quando se tentava explicar determinados acontecimentos por meio da categoria luta de classes. A propósito do movimento da Independência, lê-se que: (...) A luta de classes dos senhores de terra e de escravos para exercer a sua autoridade sobre toda a extensão do território brasileiro é longa. A independência de 1822 não contentaria as camadas médias. 
Essa revolta está claramente expressa nos movimentos provinciais da rebeldia, de que os últimos serão os dos Farrapos e dos Praieiros (...).

Em outra passagem do mesmo texto, confundia-se desejo político com análise histórica: (...) No tipo da Independência de 1822 se encontram as origens políticas das lutas sociais que hoje se travam em nosso País. A discussão sobre uma política externa independente para o Brasil, que está em todos os jornais, só tem sentido se entendemos que Independência foi aquela de 1822(...). Problemas que não teriam escapado da percepção crítica até de certos simpatizantes da obra, como o educador Anísio Teixeira, que ao se pronunciar sobre a História Nova no Conselho Federal de Educação, teria arrematado com a seguinte conclusão: (...) É, sem dúvida, tendenciosa, mas bastante inteligente...(Santos 1993: 18) ${ }^{17}$.

A esse respeito, aliás, os autores da História Nova, exceto Nelson Werneck Sodré, fizeram uma espécie de mea culpa, nos depoimentos que aditaram à edição de 1993. Joel Ruffino dos Santos destaca que o caminho aberto pela coletânea (...) um pouco pelo seu dogmatismo intrínseco e um pouco pelas circunstâncias históricas teria contribuído para a instalação e florescimento no Brasil de uma tirania pedagógica do materialismo histórico nos compêndios escolares (Santos 1993: 22). Opinião que seria partilhada por Pedro de Alcântara Figueira: (...)Um subproduto desta ideologia é esta tendência historiográfica recente que pretende fazer oposição ao que chama de 'história oficial'. Ela pretende ser representante do povo, enquanto a 'história oficial' representaria os dominadores.(...) Pobre marxismo, (...). (Figueira 1994: 44-45).

Nelson Werneck Sodré, falecido em 1999, defenderia até o fim da vida os pressupostos daquele trabalho polêmico, o que não ocorreu com os seus discípulos. De qualquer modo, temos que endossar as palavras de Maurício Martins de Mello, que em carta dirigida a Nelson Werneck Sodré, argumentou: (...) não houve uma superação, um movimento dentro da nossa historiografia, que tenha recolhido a nossa experiência e tenha tirado os fios na direção justa. Ou seja, o pupilo ao refutar o próprio mestre admitiu que até mesmo as esquerdas fizeram restrições à História Nova, sob a alegação de que seu conteúdo havia negligenciado a história operária (Sodré 1994: 302-303).

\footnotetext{
${ }^{17}$ Não tivemos acesso a esse "Parecer". Baseamo-nos nas declarações de Joel Rufino dos Santos.
} 
Do projeto da História Nova fica, sobretudo, o registro de uma empreitada idealista, reflexo dos anseios de uma militância interessada em transformar politicamente o país, à custa da transmissão às gerações futuras de uma ideologia de fundo marxista. Fundo este diluído num caldo de cultura nacionalista, onde se previa a aliança de uma burguesia nacional capaz de realizar-se como classe, aliada a uma classe tra balhadora, da qual se cobrava a aquisição de uma consciência política. Pela via da história, naturalmente.

\section{Referências Bibliográficas}

BEIGUELMAN, Paula A prática nacionalista, dever intrínseco das Forças Armadas Nacionais. São Paulo: Sindicato dos Escritores no Estado de São Paulo, 1987.

CAVALCANTI NETO, Pedro Celso Uchoa, "Visões impressionistas da História Nova do Brasil e suas circunstâncias, trinta anos depois....”. In: SANTOS, Joel Rufino dos, MELLO, Maurício, SODRÉ, Nelson Werneck, FIGUEIRA, Pedro de Alcântara, CAVALCANTI NETO, Pedro Celso Uchoa e FERNANDES, Rubem César, História Nova do Brasil 1963-1993. São Paulo: Edições Loyola: Edições Giordano Ltda, 1993. (Coleção Memória Brasileira, nº 18)

CHILCOTE, Ronald H.,O Partido Comunista Brasileiro: conflito e integração - 1922-1972. Rio de Janeiro: Edições Graal, 1982.

CRUBELLIER, Maurice “Manuels d'histoire". In: BourgulÈRe, André (dir.), Dictionnaire des Sciences Historiques. Paris: PUF, 1986.

DUARTE, Osny Pereira "O ISEB: Desenvolvimento e Reformas de Base". Revista Brasiliense, São Paulo, 47: 40, 1963.

FERNANDES, Florestan, "Reforma universitária e mudança social". Argumento, Rio de Janeiro, 1 (3): 5-22, janeiro de 1974.

FIGUEIRA, Pedro de Alcântara, "História Nova: Depoimento". In: SANTOS, Joel Rufino dos, MELLO, Maurício, SODRÉ, Nelson Werneck, FIGUEIRA, Pedro de Alcântara, CAVALCANTI NETO, Pedro Celso Uchoa e FERNANDES, Rubem César, História Nova do Brasil 1963-1993. São Paulo: Edições Loyola: Edições Giordano Ltda, 1993. (Coleção Memória Brasileira, ${ }^{\circ}$ 18)

GLATZ, Ferenc "Politics and Historical Science in the Countries of the Sivuet System". In: ___ \& Pók, Attila (org.), The soviet system and historiography (1917-1989): the influenceof marxism-leninism on the historical sciences. Budapest: Institute of History of the Hungarian Academy of Sciences, 1995. 
GUIMARÃES, Lucia Maria Paschoal, "Debaixo da imediata proteção de Sua Majestade Imperial. O Instituto Histórico e Geográfico Brasileiro (1838-1889)". Revista do Instituto Histórico e Geográfico Brasileiro, Rio de Janeiro, 156 (388), jul/set, 1995.

IGLESIAS, Francisco Historiadores do Brasil: capítulos de historiografia brasileira. Rio de Janeiro: Nova Fronteira; Belo Horizonte (MG): UFMG/PEA, 2000.

JOUTARD, Phillippe, La légende des camisards - Une sensibilité au passé. Paris: Gallimard, 1977.

MANTEGA, Guido, “ Marxismo na economia brasileira”. In: Moraes, João Quartim de (org.), História do Marxismo no Brasil - Os influxos teóricos. vol. II, Campinas (SP): Ed.UNICAMP, 1995.

MORAES, João Quartim de, "A evoução da consciência política dos marxistas brasileiros". In: (org.), História do Marxismo no Brasil - Os influxos teóricos. vol. II, Campinas (SP): Ed.UNICAMP, 1995.

NORA, Pierre, Les lieux de mémoire - La Republique. Paris: Gallimard, 1984.

OLIVEIRA, Lucia Lippi, A sociologia do Guerreiro. Rio de Janeiro: Editora UFRJ, 1995.

PRADO JÚNIOR, Caio, A revolução brasileira. São Paulo: Brasiliense, 1966. Evolução política do Brasil, São Paulo: Brasiliense, 1933. . História econômica do Brasil, São Paulo: Brasiliense, 1945.

RUBIM, Antonio Albino Canelas, Partido Comunista, Cultura e Política Cultural. Tese de doutoramento em Sociologia. São Paulo: Faculdade de Filosofia, Letras e Ciências Sociais/Universidade de São Paulo, 1986, mimeo.

SANTOS, Afonso Carlos Marques dos, “A invenção do Brasil: um problema nacional?". Revista de História, 118: 7-8, janeiro/junho de 1985.

SANTOS, Joel Rufino dos, "História Nova: Depoimento". In: Joel Rufino dos Santos, Mauricio Martins de Mello, Nelson Werneck Sodré, Pedro de Alcântara Figueira, Pedro Celso Uchoa Cavalcanti Neto e Ruben César Fernandes, História Nova do Brasil (19631993). São Paulo: Edições Loyola; Edições Giordano, 1993. (Coleção Memória no 17).

. Nelson Weneck, A verdade sobre o ISEB. Rio de Janeiro: Ed. Avenir, 1978. (Coleção Depoimentos $n^{\circ} 4$ ).

A fúria de Calibã: memórias do golpe de 64. Rio de Janeiro: Bertrand Brasil, 1994. . História da História Nova. $2^{\text {a }}$ edição, Petrópolis: Vozes, 1987.

. História da História Nova. In: Joel Rufino dos Santos, Mauricio Martins de Mello, Nelson Werneck Sodré, Pedro de Alcântara Figueira, Pedro Celso Uchoa 
Cavalcanti Neto e Ruben César Fernandes, História Nova do Brasil (1963-1993). São

Paulo: Edições Loyola; Edições Giordano, 1993. (Coleção Memória nº 17).

Introdução à Revolução Brasileira. 2a edição, Rio de Janeiro: Civilização Brasileira, 1963.

Memórias de um soldado. Rio de Janeiro: Civilização Brasileira, 1976.

Raizes históricas do nacionalismo brasileiro. Rio de Janeiro: Ministério da Educação e Cultura/ISEB, 1959. (Coleção Textos de Formação Histórica do Brasil nº 3).

TOLEDO, Caio Navarro de, ISEB: Fábrica de ideologias. São Paulo: Ed. Ática, 1977.

TORRES, Alberto, A organização nacional (Primeira Parte - A constituição). São Paulo:

Cia Editora Nacional, 1933, (Coleção Brasiliana, vol. XVII). 